DOI: 10.14526/2070-4798-2019-14-3-83-87

\title{
Methodological aspects of applying myographing system "callibri muscle tracker" in the otganization of sports training management
}

\author{
Roman E. Petrov, Ilsiyar Sh. Mutaeva*, Gazinur Z. Khalikov, Irina G. Gerasimova \\ Elabuga Institute (branch) of Kazan (Volga) Federal University \\ Elabuga, Russia \\ ORCID: 00oo-0oo1-9352-971X, romanpetrovrdr@mail.ru \\ ORCID: oooo-0oo2-9387-7033, mutaeva-i@mail.ru* \\ ORCID: 0000-0002-1898-3768, khalikov88th@qmail.com \\ ORCID: 00oo-0oo2-63348-6656, irina-chelny74@mail.ru
}

\begin{abstract}
Judging by experts' opinion, the evaluation of muscle condition is the main factor of various directions training loads optimal distribution. Confirmation of this assumption opens up new opportunities for optimizing the management of sports training in cyclic kinds of sports. The problem of expanding the use of equipment, which facilitates obtaining of operational information about the muscles state at rest and in the process of performing training loads, is particularly relevant. It is stated that the increase in the efficiency of the athletes' training process management requires deep knowledge about the inclusion of the main muscle groups in work. Materials. The study presents methodological aspects of using the myographic system "Callibri Muscle Tracker". The description of the myographic system and preliminary results of testing the device on qualified ski racers are represented. Research methods. Analysis of scientific and methodological literature on the problem of research; tests in the myographic system with determination of various parameters of studying the quadriceps muscle of thigh; statistical processing of the research results. Results. It is theoretically assumed that in order to increase the aerobic efficiency of the quadriceps muscle of thigh, it is necessary to consider the proportion of all its heads participation in the work. In this regard, it is important to determine the proportion of all the heads participation of the quadriceps muscle of thigh under loads of different directions at ski racers as the basis, which limits the physical performance of the entire muscle. Conclusion. The development and justification of the quadriceps muscle main components participation ratio determining concept are necessary for the elaboration of methodological theses for managing the process of sports training on the basis of selection and arrangement of training actions. For this purpose, it is necessary to use the certified devices and equipment and innovative methodical approaches of research.
\end{abstract}

Keywords: sport, myographic system "Callibri Muscle Tracker”, load, indicators, quadriceps muscle of thigh.

For citation: Roman E. Petrov, Ilsiyar Sh. Mutaeva*, Gazinur Z. Khalikov, Irina G. Gerasimova. Methodological aspects of applying myographing system "callibri muscle tracker" in the otganization of sports training management. Russian Journal of Physical Education and Sport. 2019; 14(3): 83-87. DOI: 10.14526/2070-4798-2019-14-3-83-87

\section{INTRODUCTION}

Modern high-performance sport is characterized by a high level of physical and mental loads demonstration. There is a significant increase in the volume and intensity of physical activity. It raises the problem of planning reconsideration and rational distribution of training and competitive loads within the macrocycle of training in sports [4, $5,7]$.

Under the influence of scientific and technological progress, which is the condition for increasing the efficiency of training management in sports, there is a tendency to accelerate the training process [13]. Specialists elaborate innovative technologies of athletes physical training based on the development of local muscular endurance [12].

Many experts offer to use cardiorespiratory adaptive capabilities of the body and types of blood circulation, as well as evaluation of functional readiness as a basis for improving the effectiveness of sports training $[1,2,3,4,6,9,10,11,14]$.

Up to the present time, it was generally believed that for improving physical capabilities of the athletes' body in different kinds of sports with demonstration of endurance, it is necessary to increase the supply of oxygen to the muscles. This would afford an opportunity to improve the adaptation of the cardiorespiratory system to aerobic loads $[1,4]$. Judging by Stickland's opinion (2003), maximum increase in the heart rate under the load 
indicates the limit of functional capabilities of the muscles involved in motor actions [15]. Current scientific studies of such authors as Polat (2016), Ettema (2017), Dahl (2017), conducted on ski racers with application of such method as testing at the limit of heart rate (HR) in the submaximal power zone, recorded the maximum oxygen consumption by muscles $[16,17,18]$.

However, modern sport requires the investigation not only of the cardiovascular system adaptive capabilities, but also adaptation and nervous regulation of muscles themselves, and the mechanisms that increase their ability for aerobic metabolism.

In the scientific works of the group of authors Yu.V. Vysochin, Yu.P. Denisenko, V.A. Chuyev (2007), as a result of fundamental research, the rate of skeletal muscles arbitrary relaxation was found, proving the relationship with the functional activity of the CNS systems. The authors determined that the rate of muscle relaxation plays a significant role in the formation of a long-term adaptation [4].

In this regard, the problem of identification and evaluation of this adaptation becomes actual. For this purpose, it is important to use different instrumental procedures. Influence of training loads on the functional indicators of athletes was considered with regard to physical performance and maximum oxygen consumption. It is also mentioned that the indicators of maximum oxygen consumption are influenced not only by exercises in aerobic mode, but also by submaximal exercises. The specialists also studied glycogen reserves, lactate concentration in muscles under loads of different intensity [14]. It is stated that the reduction of lactate in the muscles characterizes the increase in oxygen delivery. However, the data, concerning the state of the muscles under different loads, needs to be reconsidered and supplemented.

Thus, the study of the mechanism of delivering oxygen to working muscles, lactate, glycogen reserve characterizes the level of endurance demonstration under loads of different intensity. But for a more thoughtful analysis, the study of other types of adaptation, occurring in the muscles themselves, is required.

The aim of the study is to identify methodological foundations of the myographic system "Callibri Muscle Tracker" application efficiency in the process of sports training.

Research issues:

1. To determine the application significance of the myographic system "Callibri Muscle Tracker" in the process of sports training in cyclic kinds of sports.

2. To carry out the studies of the main operation parameters of the quadriceps muscle of thigh, using the myographic system "Callibri Muscle Tracker".

3. To substantiate the necessity of using the myographic system "Callibri Muscle Tracker" in cyclic kinds of sports.

\section{MATERIALS AND METHODS}

This research paper uses the myographic system "Callibri Muscle Tracker" to study the performance indicators of the quadriceps muscle of thigh (extensors of the shank) when executing bicycle ergometric test of increasing load intensity. For the research, the load was set on a bicycle ergometer of "Kettler E3" type. The initial load was 30 watts, and each subsequent load after 1 minute of execution increased by 15 watts as long as the athlete could continue to fulfil the exercise.

Figure 1 visually illustrates an example of an electromyogram (EMG) recording screen of the quadriceps muscle of the thigh, where the average and maximum amplitude of the shank extensors was recorded.

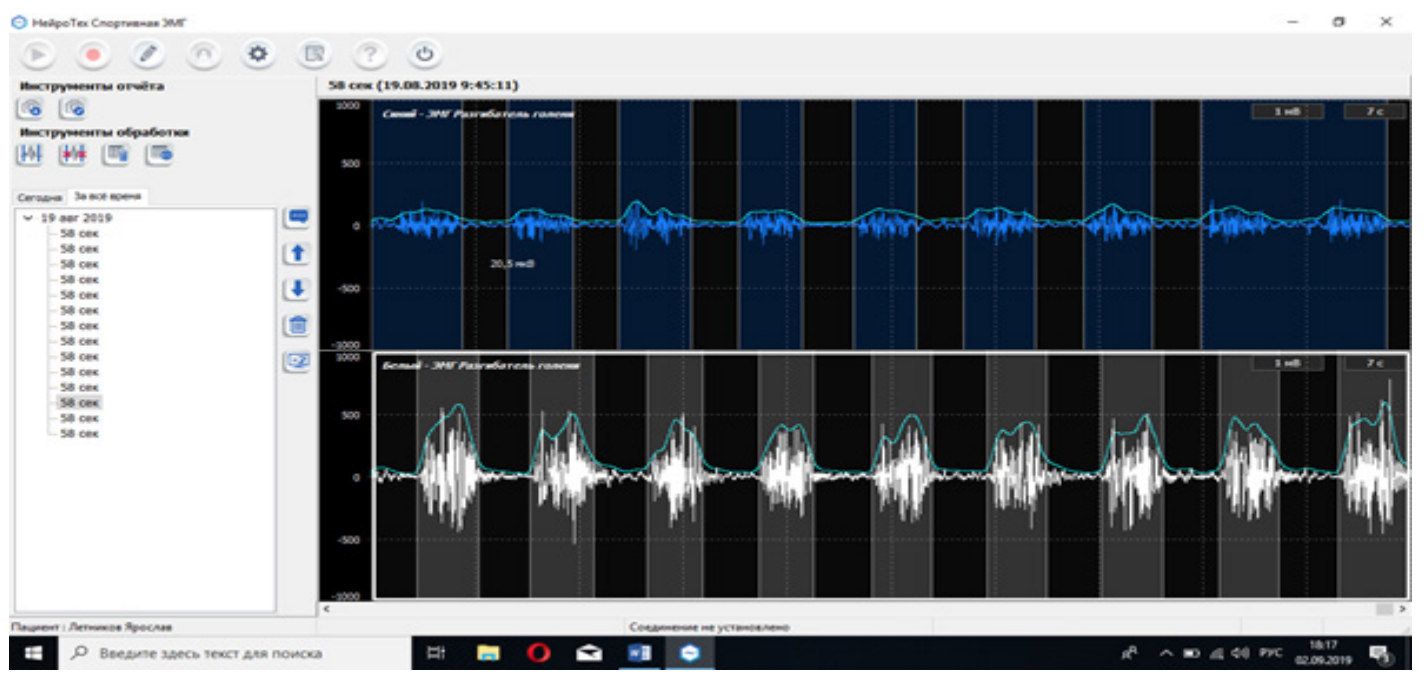

Fig. 1. Monitor screen when recording EMG of the muscle during exercise. 
The electromyogram shows the contraction of the rectus of thigh (musculus rectus femoris) in blue color and the contraction of the lateral broad muscle of thigh (musculus vastus lateralis) in white.
Table 1 presents a summary protocol of the main EMG indicators of the contraction of two heads of quadriceps thigh muscle.

Table 1. Electromyogram (EMG) indicators of quadriceps two heads contraction thigh muscle

\begin{tabular}{|c|c|c|}
\hline Investigated parameters & $\begin{array}{c}\text { Blue } \\
\text { Musculus rectus femoris }\end{array}$ & $\begin{array}{c}\text { White } \\
\text { Musculus vastus lateralis }\end{array}$ \\
\hline $\mathrm{A}($ aver.), $\mathrm{mV}$ & 94 & 328 \\
\hline $\mathrm{A}(\mathrm{max}), \mathrm{mV}$ & 203 & 670 \\
\hline $\mathrm{S}, \mathrm{mV}^{*} \mathrm{~ms}$ & 46 & 136 \\
\hline $\mathrm{T}$ (aver.), $\mathrm{s}$ & 0,5 & 0,4 \\
\hline $\mathrm{N}$ & 71 & 74 \\
\hline
\end{tabular}

The main indicators of the myographic system "Callibri Muscle Tracker" are the following: A(aver.) is the average amplitude of the quadriceps femoris contraction, measured in $\mathrm{mV}$; $\mathrm{A}(\max )$ stands for the maximum amplitude of the quadriceps femoris contraction, measured in $\mathrm{mV} ; \mathrm{S}$ is the average value of the quadriceps femoris contraction area, $\mathrm{mV}^{*} \mathrm{~ms}$; $\mathrm{T}$ (aver.) means the average time of muscle contraction, $\mathrm{s} ; \mathrm{N}$ is the number of muscle contractions per minute.

\section{Results and discussion}

The issues of athletes' adaptation to loads of different intensity in sports interested many researchers. A number of authors, substantiating physiologically the aerobic capabilities and selection of training loads, indicate the need for the correct evaluation of the training loads impact on the athletes' body using the proper physiological tests. D.V. Popov, A.A. Grushin (2014) pay particular attention to the issues of oxygen delivery to the muscles, especially to the triceps muscle of the shoulder and the outer head of the thigh quadriceps muscle. It is stated that in the outer head of the thigh quadriceps muscle, the area of fibers did not change with the increase in aerobic and power load [11].

The quadriceps muscle of thigh (musculus quadriceps femoris), the strongest muscle of the human support-motor system, has four heads: 1 . Rectus femoris (musculus rectus femoris); 2. Broad medial thigh muscle (musculus vastus femoris); 3. Lateral broad thigh muscle (musculus vastus lateralis); 4. Middle (intermediate) broad thigh muscle (musculus vastus intermedius). The main function of the quadriceps muscle of thigh is to produce extension of the shank by contraction of all its heads. The proportion of participation of all heads in the extension of the quadriceps thigh muscle shank has not been studied enough.

We can theoretically assume that in order to increase the aerobic efficiency of the quadriceps muscle of thigh, it is necessary to consider the participation ratio of all its heads in the work. In this respect, it is important to determine the participation proportion of all the heads of the quadriceps muscle of thigh under the loads of different directions at ski races as the basis, which limits the physical performance of the entire muscle.

Preliminary results carried out on a group of athletes engaged in ski racing allowed to define different participation shares of heads in the work of the quadriceps thigh muscle.

Figure 2 shows the proportion of the quadriceps thigh muscle main heads participation (musculus quadriceps femoris) in the extension of the shank.

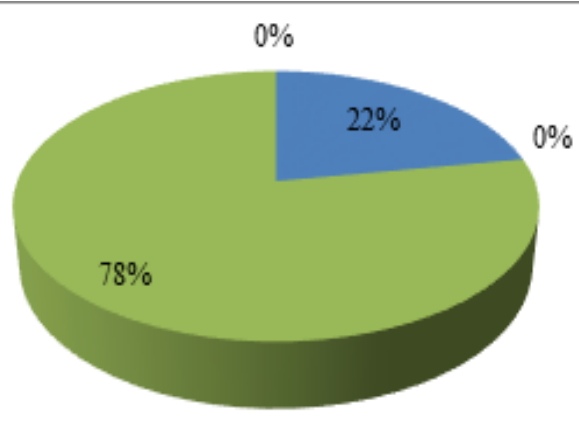

"musculus rectur fem oris

musculus vastus fem oris

M. Vastus lateralis

-M. Vastus intermedius

Fig. 2. Ratio of the quadriceps thigh muscle main heads participation (musculus quadriceps femoris) in the extension of the shank under bicycle ergometric load 


\section{CONCLUSION}

Thereby, both in theory and in practice of sports training there is a contradiction between the need to use equipment for determination of the body systems operation efficiency in the process of their long-term training and the lack or incomplete application of scientifically based technologies of integrative control and evaluation of the training influence effectiveness on the body of athletes.

The development and justification of the determining the participation rate concept of the main components of the quadriceps thigh muscle is necessary for the elaboration of theoretical and methodological theses of the management process of sports training. This can be achieved by selecting the means and determining the load in combination with periods of rest from training activity taking into account the functional state of main muscle groups. For this purpose, it is necessary to use certified devices and equipment and methodical approaches of research. The development of the concept of systematic performance control of the athletes' muscles allows to monitor and evaluate the effectiveness of the training impact and adaptation of muscles to loads.

Meaningful information about the state of muscles and comparative analysis of the study results allows to optimize the effectiveness of pedagogical influences.

The use of the myographic system "Callibri Muscle Tracker" for determination of the contractile abilities of the quadriceps thigh muscle gives an opportunity to identify the influence of contractile muscles characteristics on the growth of athletes sports qualification.

A theoretical analysis of the using possibilities the myographic system "Callibri Muscle Tracker" in the process of sports training in cyclic kinds of sports was carried out.

Preliminary studies of the contraction of the quadriceps thigh muscle heads with increasing bicycle ergometric load were conducted using the myographic system "Callibri Muscle Tracker". The main parameters which characterize shank extensors were obtained.

The necessity of using the myographic system "Callibri Muscle Tracker" in sports training of ski racers in further studies was revealed.

\section{REFERENCES}

1. Vanyushin Yu.S. Compensatory-adaptive reactions of cardiorespiratory system. Doctor's thesis. Kazan. 2001: 323.

2. Vanyushin M.Yu., Elistratov D.E. Influence of increasing power load on cardiorespiratory system of sportsmen with different types of blood circulation. Fundamental'nye issledovaniya. 2012; 3: 241-244 (In Russ.).
3. Vakhitov I.Kh. Pumping function of the heart depending on the age of initiating muscle training. Doctor's thesis. Kazan. 2005: 45.

4. Vysochin Yu.V. Fiziologicheskie osnovy special'noj podgotovki futbolistov [Physiological bases of special training of football players]. Naberezhnye Chelny: KAMGIFK. 2007 (In Russ.).

5. Semenov V.G., Vrublevsky E.P. Regularities of adaptive variability of muscle strength of female sprinters in the process of sportsmanship formation. Teoriya I praktika fizicheskoj kul'tury = Theory and practice of physical culture. 2000; 9: 22-24 (In Russ., In Engl.).

6. Gizatullina Ch.A., Mutaeva I.Sh. Ways of individualization of training the sprinters on the basis of registration of typological characteristics of the blood circulation. Pedagogiko-psihologicheskie I medico-biologicheskie problemy fizicheskoj kul'tury I sporta $=$ Pedagogico-psychological and medico-biological problems of physical culture and sports. 2012; 3(24): 11-119. URL: http://kamgifk. $\mathrm{ru} /$ magazin/ journal.htm (In Russ., In Engl.).

7. Kuznetsova Z., Kuznetsov A., Mutaeva I., Khalikov G., Zakharova A. Athletes preparation based on a complex assessment of functional state. In Proceedings of the 3rd International Congress on Sport Sciences Research and Technology Support. SCITEPRESS. 2015: 156-160.

8. Mutaeva I.Sh., Kuznetsov A.S., Konovalov I.E., Khalikov G.Z. Evaluation of functional readiness of track-and-field athletes training for endurance. Fundamental'nye issledovaniya. 2013; 6: 2: 440-444.

9. Petrov R.E., Bekmansurov R.Kh. Dynamics of heart rate at stepwise increasing load among ski racers in the preparatory period. Sovremennye naukoemkie tehnologii. 2017; 2: 147-151 (In Russ.).

10. 9. Petrov R.E., Mutaeva I.Sh., Ionov A.A. Determination and evaluation of aerobic threshold and potential capabilities of the cardiac system of skiers-riders (boys) based on the use of step-increasing Bicycle ergometric load. Pedagogikopsihologicheskie I mediko-biologicheskie problem fizicheskoj kul'tury I sporta $=$ The Russian Journal of Physical Education and Sport. 2018; 13(2): 198206. DOI 10.14526/02_2018_326 (In Russ., In Engl.).

11. Popov D.V., Grushin A.A., Vinogradova O.L. Fiziologicheskie osnovy ocenki aerobnyh vozmozhnostej I podbora trenirovochnyh nagruzok v lyzhnom sporte I biatlone [Physiological basis of evaluating aerobic capabilities and selection of training loads in skiing and biathlon]. Moscow: Soviet sport. 2014: 17-20.

12. Seluyanov V.N., Liu C., Vasilyev A.V., Dias S. Innovative technology of physical training of football players on the basis of development of local muscular endurance. Fizicheskaya kul'tura: 
vospitanie, obrazovanie, trenirovka. 2013; 34: 4748 (In Russ.).

13. Tikhomirov A.K. Upravlenie podgotovkoj $\mathrm{v}$ sporte: monografiya [Management of training in sport: monograph]. Moscow State Academy of Physical Culture. Book and Business. Malakhovka. 2010: 230.

14. Jansen P. ChSS, laktat I trenirovki na vynoslivost': perevod s anglijskogo [Heart rate, lactate and endurance training: translated from eng.]. Murmansk, Tuloma. 2006: 160.

15. Stickland M.K., Petersen S.R., Haykowsky M.J., Taylor D.A., Jones R.L. The effects of cycle racing on pulmonary diffusion capacity and left ventricular systolic function. Respir Physiol
Neurobiol. 2003; 138: 291-299.

16. Polat M. An examination of respiratory and metabolic demands of alpine skiing. Journal of Exercise Science and Fitness. 2016; 14(2): 76-81.

17. Ettema G., Kveli E., Øksnes M., Sandbakk $\varnothing$. The role of speed and incline in the spontaneous choice of technique in classical roller-skiing. Human Movement Science. 2017; 55: 100-107.

18. Dahl C., Sandbakk Ø., Danielsen J., Ettema $\mathrm{G}$. The role of power fluctuations in the preference of diagonal vs. double poling sub-technique at different incline-speed combinations in elite crosscountry skiers. Frontiers in Physiology. 2017; 8: 94.

\section{Submitted: 12.08.2019}

Author's information:

Roman E. Petrov - Candidate of Pedagogics, Associate Professor, Elabuga Institute (branch) of Kazan (Volga) Federal University, 423600, Russia, Elabuga, Kazanskaya str., House 89, e-mail: romanpetrovrdr@ mail.ru

Ilsiyar Sh. Mutaeva - Candidate of Bbiological Sciences, Professor, Elabuga Institute (branch) of Kazan (Volga) Federal University, 42360o, Russia, Elabuga, Kazanskaya str., House 89, e-mail: mutaeva-i@ mail.ru

Gazinur Z. Khalikov - Candidate of Pedagogics, Senior Lecturer, Elabuga Institute (branch) of Kazan (Volga) Federal University, 42360o, Russia, Elabuga, Kazanskaya str., House 89, e-mail: khalikov88th@ qmail.com

Irina G. Gerasimova - Candidate of Pedagogics, Elabuga Institute (branch) of Kazan (Volga) Federal University, 423600, Russia, Elabuga, Kazanskaya str., House 89, e-mail: irina-chelny74@mail.ru 